\title{
How Behavioural Economics Relates to Psychology - Some Bibliographic Evidence
}

\author{
Fabian Braesemann ${ }^{\mathrm{a}}$ \\ ${ }^{a}$ Oxford Internet Institute - University of Oxford \\ fabian.braesemann@oii.ox.ac.uk, ORCID-ID: 0000-0002-7671-1920
}

This is an Accepted Manuscript of an article published by Taylor \& Francis Group in Journal of Economic Methodology. The original source of publication is:

Braesemann, F. (2019). How behavioural economics relates to psychology-some bibliographic evidence. Journal of Economic Methodology, 26(2), 133-146.

Available online: https://www.tandfonline.com/doi/full/10.1080/1350178X.2018.1511257

\begin{abstract}
Whether behavioural economics has a fundamental influence on economics is debated by behavioural and heterodox economists as well as by methodologists and historians of economics. At the core of this debate is the question whether behavioural economics is shaped by large-scale content imports from psychology, or whether these transfers have been too selective to challenge dominant approaches in economics. This study contributes to the debate in analysing a variety of bibliographic data from the disciplinary boundary between economics and psychology. Two datasets from the boundary of behavioural economics and psychology are compared to sets of economic and psychology publications in quantifying the use of mathematics, the share of empirical contributions, the authors' academic background, and their cross-citations via network analysis. In contrast to proposals made by some methodologists and behavioural economists, the statistical results confirm content transfers from psychology via behavioural economics only to a limited extend. The observed level of interaction provides evidence for a selective import of specific psychological findings by a small number of established investigators in behavioural economics. These findings were then intensively debated as divergences from rationality within the growing, but econ-centered community of behavioural economists.
\end{abstract}

JEL classification: A 12, B 4, C 8

Keywords: Economic methodology $\bullet$ Citation analysis $\cdot$ Behavioral economics $\cdot$ Social network analysis $\cdot$ Bibliographic data mining

Code and Data: www.github.com/Braesemann/CitationAnalysis

\section{Introduction}

Behavioural economics is established as a central field of research in today's economics. It has not only become an important part of economic research and graduate teaching, but has also influenced the public opinion about economics. This rising importance is emphasised by some scholars speaking of a "behavioral revolution" (Berg, 2003). Its rise has led to a lively discussion 
about the innovative potential of behavioural economics based on its supposedly deep-rooted relation to psychology and on the influence on the development of economics.

Main advocates of a profound influence on the development of the whole discipline are the leading behavioural economists themselves (Rabin 1998, Kahneman 2003a, Kahneman 2003b, Camerer and Loewenstein 2004). For example, Camerer (1999) predicts "a healthy reunification of psychology and economics" under the roof of behavioural economics (p. 10 577). Other researchers are more sceptical and criticize behavioural economics as "neoclassical economics in disguise" (Berg and Gigerenzer, 2010). Sharp criticism comes from heterodox economists, who consider it "a means of defending orthodoxy" (Earl, 2010, p. 216) or "too solidly rooted in neoclassical theory to escape from being false knowledge" (Lee, 2012, p. 343).

Historians and methodologists of economics take different perspectives in analysing the potential influence of behavioural economics. Building on Lakatos' methodology of degenerative and progressive research programs, Dow (2014) assesses that behavioural economics "falls short in Lakatosian terms" (p. 39). Other scholars highlight the common roots of psychology and economics in the late 19th and early 20th century (Bruni and Sugden 2007, Hands 2009, Thaler 2016). Sent (2004) concludes: "Behavioral Economics: How Psychology Made Its (Limited) Way Back Into Economics". David Colander interprets new sub-fields like behavioural economics as a sign of the "Death of Neoclassical Economics" (Colander, 2000a) or the rise of "New Millenium Economics" (Colander, 2000b).

Davis (2006) proposes an empirical criterion to evaluate the influence of new research programmes in economics. He argues that "fields with high levels of imported contents may be said to be comparatively heterogeneous" (p. 7) and that "cross-boundary content transfers ... [set] up genuine competition between approaches" (p.9). These competing approaches "may be said to constitute genuinely different approaches in virtue of the different conceptual and theoretical foundations of different fields [they import]" (ibid). By this criterion, behavioural economics would constitute such a competitor as it "receives its impetus from recent psychology" (ibid).

This idea serves as research hypothesis for the study presented here, as it is narrowed to the concrete empirical claim of content imports from psychology to economics via behavioural economics. This criterion is at the core of the statements mentioned above: a potential major influence on the methodology of economics by behavioural economics requires large-scale content imports from psychology. On the contrary, critics assert that the psychological contents transferred by behavioural economics are in fact highly selective and that dominant approaches in economics 
remain unchallenged.

It is the aim of this study to investigate the relation of behavioural economics to psychology at the boundary of both disciplines with quantitative means in order to find tangible evidence of the degree of interaction between the disciplines. This analysis is complementary to thorough historical-methodological assessments as it yields new insights which help to discriminate between different narratives about the relation between psychology and economics.

In summary, this study provides quantitative measures on the relation between economics and psychology at the boundary of both disciplines. Differences between behavioural economics articles, psychology publications from the boundary of the discipline, and random selections of economics and psychology articles are investigated with respect to the use of mathematics, the share of empirical contributions, the authors' academic background, the proportion of references to other contributions in economics and psychology and their cross-citation links.

Taking the evidence of the different quantifications together, the results suggest selective imports of psychological content via behavioural economics. Cross-disciplinary contributions from psychologists have been centred on publications from a small number of behavioural economists (e. g. Kahneman and Tversky) that bridged the boundary between the disciplines and became part of the canon of behavioural economics.

This study introduces a number of quantifications and tools from bibliometrics, network analysis and computational social sciences, which scholars in the methodology and history of economics have recently begun to explore (Aistleitner et al. 2015, Angrist et al. 2017, Claveau and Gingras 2016, Duarte and Giraud 2016, Fourcade et al. 2015, Gingras and Schinckus 2012, Glötzl and Aigner 2015, Herfeld and Doehne 2017, Kapeller et al. 2016, Panhans and Singleton 2016). ${ }^{1}$

To date, very few studies have taken a bibliographic perspective on the influence of behavioural economics: Laibson and Zeckhauser (1998) evaluate the impact of Amos Tversky on the emerging field of behavioural economics. The authors use data from the Social Science Citation Index to review Tversky's most cited contributions in order to identify fertile areas for behavioural economics research. While the article provides a thorough overview of the evolving discipline, the citation analysis is limited to counting the number of citations per article. In the same spirit, Heukelom (2007) provides quantitative evidence of the scientific importance of famous behavioural economists by using plain Google search queries. Other studies that consider a larger number of behavioural economics contributions are those by Berggren (2012) and Grossmann (2014). ${ }^{2}$ Both studies investigate the extent of normative judgements with respect to paternalistic economic 
policies in behavioural economics, in conducting a literature analysis on selections of behavioural economics articles.

The study is organised as follows: the next section describes the data selection process. The results are presented in section 3 and section 4 discusses the results, mentions limitations of the quantitative approach and outlines potential future research.

\section{Data Selection}

To approach the research question by a citation analysis, it is necessary to identify articles at the boundary of both disciplines. Since there is no common classification of articles in economics and psychology, which could be used to identify behavioural economics contributions and psychological articles at the boundary to economics at the same time, an indirect approach has been developed based on citation-relations in the Web of Science database. ${ }^{3}$

In a first step, survey articles and reviews on the history of behavioural economics have been searched for the most important contributions to the emerging discipline, as determined by the reviews, see table 1. ${ }^{4}$ The article "Prospect Theory: An Analysis of Decision Under Risk" (Kahneman and Tversky, 1979), for example, was mentioned in 10 out of 11 reviews as fundamental for the discipline and has been cited more than 14,000 times by August 2017. This selection, thus, represents fundamental foundational articles that unambiguously belong to behavioural economics. In order to build a dataset at the disciplinary boundary from this selection, all articles were collected that refer to at least two of the foundational articles and that were published in very prestigious economics- or psychology journals in a period from 1974 to $2013 .{ }^{5}$ The journals are listed in table 2 .

\section{TABLE 1 AND 2 ABOUT HERE}

The resulting dataset consists of 122 articles published in economics journals and 130 articles published in psychology journals. ${ }^{6}$ Since these publications refer to fundamental articles that deal with topics like conceptions of decision under risk, which are relevant for psychology as well as economics, they can be presumed to be at the boundary of both disciplines.

It should be noted at this point that the dataset is a selection of articles with specific properties that allow to consider them as being relevant for the boundary of economics and psychology. However, it is not claimed that they constitute the entire set of publications on topics relevant for both disciplines. ${ }^{7}$ Given the difficulties in identifying articles of the relevant sub-disciplines within 
economics and psychology simultaneously, the data selection based on citations to foundational behavioural economics articles is, nonetheless, advantageous compared to other methods commonly used in citation analysis. ${ }^{8}$ The indirect approach allows to model the boundary zone at the edge of both disciplines in terms of articles that are related to each other, but published in journals of different disciplines. ${ }^{9}$ Additionally, two random selections of articles from economics and psychology journals have been collected.

In summary, four sets of articles are compared to understand the relation of behavioural economics to psychology: the behavioural economics set consists of 122 articles published in prestigious general interest economics journals, relating to the foundational behavioural economics contributions mentioned above. Similarly, the psychology boundary set, for simplicity called economic psychology, consists of 130 papers from prestigious psychology journals relating to the foundational behavioural economics articles. Random selections of similar size from the same journals are used to reveal differences between behavioural economics and economics in general, and between psychology and the related psychology contributions at the disciplinary boundary: 120 economics articles and 121 psychology articles. These two sets represent common contributions in both disciplines. The behavioural economics set represents the sub-discipline of behavioural economics. The economic psychology set is not a representative selection of psychology articles, but shifted towards the boundary to economics. Considering this selection of psychology publications, that is defined by a proximity to economics, allows to understand the properties of psychology publications that are more likely to be recognised by (behavioural) economists.

\section{Results}

\section{Mathematical and Empirical Modelling}

One dimension that differentiates the articles of the different categories is the use of mathematical modelling and the relation to empirical data. ${ }^{10}$ This dimension is quantified in table 3 . Part (a) displays the number of articles that include a mathematical model: the ratio in the set of randomly selected economics articles is slightly higher than in the set of behavioural economics articles. In both sets, the majority of articles use mathematical models. In contrast, only a minority of contributions in psychology include mathematical equations. The differences between both behavioural economics and economic psychology, and between the two psychology data sets are significant, as shown by the pairwise $\chi^{2}$-tests. Similar results can be observed, when the use of mathematics is compared across theoretical articles as shown in table 3b. 


\section{TABLE 3 ABOUT HERE}

The results with respect to the relation to empirical data (table 3c) show a similar pattern. Within the set of behavioural economics contributions, a majority of articles is related to empirical data, leading to a ratio that is only slightly different than that of the balanced economics set. The behavioural economics contributions, however, are significantly less related to empirical data than the publications in economic psychology.

These observations reveal that behavioural economics is methodologically similar to economics in general with respect to the use of mathematical modelling and the relation to empirical data. At the same time, behavioural economics is less related to empirical or experimental data than its counterpart at the disciplinary boundary. Moreover, the economic psychology publications are more concerned with analysing experimental data than psychology in general, but differ even more with respect to the use of mathematical terminology.

\section{Cross-Discipline Contributions and Citations}

The openness of a discipline to content imports from other fields can be assessed by the portion of articles that successfully bridge the gap between the disciplines. That concept is quantified in this study in two ways:

First, a score is computed that captures the authors' scientific background based on past publications associated to them listed in the Web of Science database. Such an indirect approach has been chosen, as there is no comprehensive dataset available that would include the education of the researchers under consideration, particularly with respect to earlier contributions. The academic background of an author is defined as the number of publications in economics (psychology) minus the number of articles in psychology (economics) divided by the total number of publications (the ten first publications of an author are considered, publications in other than the two relevant disciplines are excluded). ${ }^{11}$ As this score is computed on an individual author level, a weighted average is calculated to construct an article-based score according to the following formula:

$$
\pi_{k}^{*}=\left(\pi_{k}+1\right) \cdot \frac{1}{2}=\sum_{i=1}^{n} \alpha_{i} \cdot \underbrace{(n+1-i) \cdot \frac{1}{n(n+1) / 2}}_{\text {weighting }}
$$

The normalised (inverted) paper score $\pi_{k}^{*} \in[0,1]$ and reflects the academic background of all $n$ authors of an article $k$. It is defined as the sum of all individual authors' scores $\alpha_{i}$ multiplied with a weighting factor that takes the different number of authors per article into consideration 
and the position of an researcher in the authors' list: the individual score of the first author gets the highest weight, the second author is weighted second-highest and so on. ${ }^{12}$ An article published in a discipline that has been written solely by researchers from that field gets a value of 0.0. If that article was written solely by researchers from the other discipline, it would get a value 1.0. Values in between indicate collaboration between both disciplines.

Secondly, the ratio of the number of cross-discipline references divided by the within-discipline references is calculated for each article. ${ }^{13}$ For the case of an economic article, this indicator has a value of 0.0 , if there are no references to psychology. It would take a value of 1.0 , if there are an equal number of citations to contributions from economics and psychology, and values larger than 1.0 in case that there are more cross-discipline citations than economic references in the paper.

\section{FIGURE 1 ABOUT HERE}

Figure 1 provides summary statistics of the two indicators below the panel and shows their development over time for the four sets of articles represented by dots of differing size, according to an article's paper score. Note that random noise has been added to each graph in order to reduce over-plotting and that the y-axis is on a logarithmic scale to increase readability. Squared brackets at the lower end of each plot show the amount of random variation of those articles that have no cross-discipline references. Additionally, small grey lines at the right side of each plot show the distribution of the cross-discipline references and help to reveal differences between the sets.

As expected, the share of both cross-discipline references and multi-disciplinary contributions in the sets displayed in the panels A and B are much higher than in the respective sets below. Moreover, there are significant differences between the contributions in behavioural economics and economic psychology. The smoothed trend line shows a decreasing ratio of cross-discipline references for the behavioural economics set, starting from an average value of around 0.2 in the 1980s to only 0.05 after 2010. Noteworthy is that number of articles that include no references to psychology at all is increasing over time. The articles written by Daniel Kahneman and/or Amos Tversky are highlighted in orange and show no specific pattern in the behavioural economics set with three contributions below and three above the trend line.

In contrast, the economic psychology articles refer more often to economics publications, if the mean and median values are compared. This result could be expected as the articles in this set are collected based on a proximity to economics. Notable is the lack of any significant trend over time, indicating a constant interest in economics contributions. Similarly, there is a constant 
non-interest in economics from psychology in general, as can be seen in panel D.

While economics also lacks significant interest in psychology, as measured by citations, there is a positive time trend in the data in panel $\mathrm{C}$, which is due to a number of publications that refer to some psychology sources, starting from the year 2000. This increasing time trend could be seen as a signal for the success of behavioural economics to raise some attention to findings from psychology.

Comparing the summary statistics of the paper score variable, both economics and psychology exhibit low values. While still on a low level, there is a notable difference in the median values of behavioural economics and economic psychology. The significantly higher value of the behavioural economics set is partly due to the contribution of very prominent psychologists like Daniel Kahneman and Amos Tversky who succeeded in contributing to the behavioural economic literature. Conversely, the publications in economic psychology are to a higher degree composed by scholars within the field than from outsiders.

\section{Citation Network}

The articles from behavioural economics and economic psychology are both from the boundary of the disciplines and should be closely related to each other. Accordingly, their cross-citation pattern could reveal the pathways of content transfer from psychology to economics. This is displayed in the network visualisation in figure 2. It consists of 493 articles (nodes) that are connected via 740 citation-relations (directed links). ${ }^{14}$ Nodes that have no connections to other nodes in the network, i. e. the vast majority of economics and psychology articles in the data set, have been removed. The nodes are coloured to represent the four sets and the Kahneman/Tversky publications. Larger nodes stand for articles with a higher paper score. The colour of the links reflects within- and cross-discipline references: for instance, a link connecting two behavioural economics articles is displayed in red. Thick grey links signalize a cross-disciplinary relation from a psychology contribution to economics or vice versa. The nodes are positioned according to the Fruchterman-Reingold algorithm (Fruchterman and Reingold, 1991). This algorithm aims to improve the readability of the graph by placing the nodes in a way to minimize the overlap of links. Highly intertwined regions are central regions in the network with many connections between nodes.

\section{FIGURE 2 AND 3 ABOUT HERE}

The network illustrates the high level of connectivity within the sets of behavioural economics 
and economic psychology publications. The nodes within each set are closely related to one another, while a few highly central articles (hubs) bridge the gap between the disciplines. The network connections at the boundary of the disciplines are far from random and exhibit a smallworld architecture (Watts and Strogatz, 1998). It is worth noting that the Kahneman/Tversky publications are central hubs in the network. This is also true for other articles with a high paper score, as indicated by larger nodes in the centre of the network.

The relation between paper score and network centrality is further examined in figure 3 . It relates paper score and betweenness centrality, an indicator of network centrality that measures the total number of shortest paths between pairs of nodes that pass through an article $i$ (Freeman 1977, Newman 2001). As in figure 1 , the y-axis is on a logarithmic scale and additional random noise helps to reduce overplotting. The size of the nodes corresponds to the number of cross-discipline ingoing links (in-degree centrality).

As can be seen from the figure, there are in fact only a few articles that combine a high betweenness centrality and a high cross-discipline in-degree centrality. The six articles with the highest number of cross-discipline in-links are emphasised in the graph and summary statistics of these publications are listed below the panel. These six articles constitute one percent of the data set, but account for more than $40 \%$ of the cross-discipline citations.

These articles are central in the citation network. All of them are published in economics journals, five of them include a high share references from psychology and are written by psychologists or in multi-disciplinary collaboration. These articles clearly take an important position in transferring concepts from psychology to economics. However, looking at the authors of these contributions, it becomes clear that all of them are written by highly influential scholars of behavioural economics, in particular Daniel Kahneman, George Loewenstein, Paul Slovic and Amos Tversky.

Hence, the network analysis provides evidence for a high level of interaction at the disciplinary boundary, which is mainly driven by the exceptional importance of a limited number of bridging articles from highly established scholars.

\section{Discussion}

In contrast to the hypothesis put forward by Davis (2006), the empirical results do not confirm high levels of cross-boundary content transfers from a genuinely different field. Instead, the data suggest that, while there is interaction at the boundary between economics and psychology, it is 
mainly driven by selective imports through a few highly important articles.

The use of mathematical terminology and the relation to empirical data in behavioural economics is relatively similar to economics in general. This result points towards a continuation of economic research methods in behavioural economics, rather than to an alternative methodology, focused around experimental studies. In comparison, almost three out of four articles from the psychology contributions at the boundary to economics present empirical data, mostly from experiments.

On the other hand, behavioural economics refers to a significantly higher degree to contributions from psychology than other parts of economics. However, the average share of cross-discipline references in the data set dropped by a factor of four from 1980 to 2010, while this value stays largely constant in the economic psychology set. This implies that behavioural economics links to psychology have diminished over time, so that it has become more econ-centred.

Looking at the interactions at the boundary of the disciplines reveals that the content import from psychology to behavioural economics is largely due to a small number of articles. These are composed by a few highly established scholars with a multi-disciplinary background who could successfully bridge the gap and transfer psychological findings to economics. In comparison to the random selection of economics articles, these bridging behavioural economics articles refer substantially to contributions from psychology.

Taken together, the quantitative evidence suggests selective imports of psychological findings by a small number of established and highly cited behavioural economists in accordance with Camerer (1999), who defines the aim of behavioural economics as "[finding] mathematical alternatives with firm psychological foundations to rationality assumptions" (p. 10 577) and Rabin (1998), who assesses that "some important psychological findings seem tractable and parsimonious enough that we should begin the process of integrating them into economics" (p. 13). These findings were then intensively debated as divergences from rationality within the growing, but econ-centered community of behavioural economists (Heukelom, 2007). ${ }^{15}$

This study marks an example of a more evidence based meta-discussion about the scientific impact of behavioural economics. In doing so, the study builds on a number of assumptions, particularly with respect to the data selection, which are explained in section 2 and further detailed in the notes. Consequently, the results should be empirically verified and openly discussed by practitioners from the field and methodologists alike. ${ }^{16}$ 


\section{Acknowledgements}

I am grateful for the feedback received by two anonymous reviewers that helped to greatly improve this manuscript. Moreover, I would like to thank Till Düppe and Hansjörg Klausinger for the advice on earlier versions of this work, which was developed during my $\mathrm{PhD}$ studies at Vienna University of Economics and Business. I would also like to thank Fabian Stephany and Peter Hasenhuetl for many helpful comments. 


\section{Notes}

${ }^{1}$ This rise in quantitative approaches to the history of economics has led Beatrice Cherrier to raise the question whether a quantitative turn is going on in the history of economics (Cherrier, 2015).

${ }^{2}$ Berggren (2012) manually classifies 323 out of 8,000 top-economics articles, while Grossmann (2014) considers 94 articles in detail.

${ }^{3}$ Using a more direct approach, e.g. based on JEL-classification, as it has been done by Grossmann (2014), is not an option in the case under investigation, since JEL-codes are only available for economics articles (and the coverage in economics itself is not very high, particularly for older contributions that might be particularly important bridging articles of behavioural economics). Moreover, Cherrier (2017) points out that JEL-codes do not remain stable and are subject of discussion themselves.

It is also not possible to build a dataset on plain keyword search, because of the different vocabulary used in economics and psychology to describe similar concepts; consider two examples: (a.) prospect theory vs. lossaversion and mental accounting, (b.) learning and evolution vs. generalized reinforcement and replication by fitness. Further examples are provided by Camerer (1999).

${ }^{4}$ The historical reviews considered are: Angner and Loewenstein (2007), Beck (2014), Bruni and Sugden (2007), Camerer (1999), Camerer and Loewenstein (2004), Heukelom (2014), Kahneman (2003b), Kahneman (2003a), Pesendorfer (2006), Rabin (1998) and Samson (2014).

Only those articles have been considered as foundational that are mentioned as fundamental to behavioural economics or an important sub-field of it in at least three reviews and that, on average, got at least 15 citations per year.

${ }^{5}$ Note the following typology of potential citation relationships: 1 . Given that an article $A$ cites usually more than one article $B$, there could be an asymmetric $A$ cites $B$ relation between one $A$ and several $B$ s. 2 . Two cited articles $B_{1}$ and $B_{2}$ can be related by a $B_{1}$ and $B_{2}$ are cited by $A$ relation. 3 . Each $B$ can be related to more than one $A$ by an asymmetric $B$ is cited by $A$ relation. 4. Two citing articles $A_{1}$ and $A_{2}$ can be connected by a symmetric $A 1$ and $A 2$ both cite $B$ relation. Note that the inclusion criterion for the articles in the data set is according to the following rule (based on 1.): an article $A$ is considered, if it cites at least two articles $B_{i}$ and $B_{j}$ from the list of foundational articles, and if it is published in a journal listed in table 2.

The minimal threshold of two references to foundational articles was chosen to reduce the noise due to strategical citations from articles that have nothing to do with topics relevant for behavioural economics or psychological articles at the boundary to economics.

Field journals that were founded after the emergence of behavioural economics with the aim to host contributions in the field like the Journal of Economic Psychology, Psychology and Marketing or Journal of Behavioural and Experimental Economics were not considered as the the focus is on more general interest journals.

${ }^{6}$ This selection represents a trade-off: While it would have been possible to increase the number of articles by considering more foundational articles or journals, or to choose a different threshold for the number of references to foundational articles, it would have been hard to argue that datasets composed differently better represent relevant at the disciplinary boundary. For example, loosening the references-threshold from two to one leads to a larger, but also skewed dataset of 443 publications in economics and 753 in psychology. The additional articles disproportionately often refer to the top foundational articles (Kahneman and Tversky, 1979) and (Tversky and Kahneman, 1974), which indicates strategic citation behaviour to particularly highly cited articles. This is confirmed by manual inspection of a selection of these additional articles. They do not appear to be as tightly related to "behavioural" topics as the smaller dataset of 252 articles. The complete dataset including all variables is available from the author upon request.

${ }^{7}$ The whole idea of a strict boundary between (sub-)disciplines should not be taken to literate. Given the dynamic evolution of scientific disciplines, see for example Angrist et al. (2017) or Claveau and Gingras (2016), one should rather think of a transition from the core of one field to another. The boundary, as a metaphor, describes this zone of more or less smooth transition. Having this in mind, the articles under consideration can be said to come from the transitional zone between economics and psychology.

${ }^{8}$ The plain classification of articles to the category a journal belongs to would not help us to identify subdisciplines. Keyword- or JEL-based classification are, as explained in footnote 3, also not applicable.

${ }^{9}$ Robustness checks support the presumption that data selection procedure identifies relevant behavioural economics articles (More information on the robustness checks is available on request):

(a.) The share of references to most of the foundational articles is similar for both sets. 
(b.) For the articles with JEL-classification: the majority (76\%) refers to "typical" behavioural economics categories like "Design of Experiments", "Information, Knowledge, and Uncertainty" or "Intertemporal Choice".

${ }^{10}$ To assess the use of mathematics and empirical data, for each article two simple binary variables are manually assigned. If an article discusses a concept in mathematical terms, e.g. by a utility function, it was classified as using mathematical modelling. If there is some relation to empirical data, e.g. the reference to an experiment, it was labelled as an empirical paper. Information on both variables is not available in bibliographic databases, but had to be inferred from the articles themselves. However, in a recent article, Angrist et al. (2017) present a machine-learning approach to estimate whether an article is empirical or theoretical.

${ }^{11}$ The following examples illustrates the approach: An author $A$ published his first ten articles in economics and gets a score of $\frac{10-0}{10}=1.0$. Another author $B$ published 6 articles in economics journals and 4 in psychology - her score would be $\frac{6-4}{10}=0.2$. A third author $C$ published eight articles in total, all in psychology journals and would end with a score of $\frac{0-8}{8}=-1.0$. Please note that, when aggregated on an article level, the score is normalized on a scale between 0 and 1. An article published in an economics journal written by e.g. one psychologist $\left(\alpha_{i}=-1\right.$, first author) and one economist ( $\alpha_{j}=+1$, second author) would then have a paper score of $\pi_{k}^{*}=\frac{1}{3}$. Moreover, the scale is inverted to ease the interpretation.

${ }^{12}$ This design of the paper score gives most weight to the first author. As a robustness check, other weighting schemes (a. plain average of all authors individual scores and b. just the first authors' individual score) have been computed: the results are robust against such variation.

${ }^{13}$ To construct measures of cross-disciplinary references, common journal rankings, which categorise journals into disciplines, have been considered. Such journal-lists (see SCI 2014) are the basis for classifying the references of an article into either economics or psychology publications. In the references of each article in the database, the journals are specified by abbreviations (see http://bit.ly/WoS_abbr). Combining the journal ranking and the abbreviation list, in total 202 economics journals and 231 psychology journals could be identified. References that link to articles from other disciplines or non-journal publications were not considered to keep the data processing feasible. For details on the construction of a network structure see footnote 14 .

${ }^{14}$ The network was constructed by creating an identifier of the form "last name of first author" + "initials of other names of first author", "publication year", "journal abbreviation", "V" + "volume", "P" + "first page of the article", for each article in the dataset (this is the identifier used by Web of Science to relate articles to each other, e.g. "HARRIS JR, 1970, AM ECON REV, V60, P126"). The identifiers can be used to build the network from the column "references" which is available in the bibliographic database.

${ }^{15}$ Heukelom (2007) writes on page 41: "Kahneman, Tversky, and Thaler propose a research agenda that sets economics off in a different direction, but at the same time saves traditional economics as the objective anchor by which to stay on course".

${ }^{16}$ Further research is necessary to test the empirical claims made in this study: such research could explore, for example, other methods to identify potentially interdisciplinary sub-disciplines within economics, as the citationbased method presented here sensibly relies on assumptions, e.g. in the composition of the foundational articles set. The inference of an author's academic background and the share of interdisciplinary references could be extracted algorithmically. Following research machine-learning approaches (Angrist et al., 2017), additional data could be generated by the application of statistical learning approaches (e.g. by using text mining to infer the use of mathematical modelling).

\section{References}

Aistleitner, M., Fölker, M., Kapeller, J., 2015. Die Macht der Wissenschaftsstatistik und die Entwicklung der Ökonomie. Schmollers Jahrbuch 135, 111-132.

Angner, E., Loewenstein, G., 2007. Behavioral Economics. In: Handbook of the Philosophy of Science. Elsevier, Amsterdam, pp. $641-690$.

Angrist, J., Azoulay, P., Ellison, G., Hill, R., Lu, S. F., 2017. Economic Research Evolves: Fields and Styles. American Economic Review 107 (5), 293-97.

Beck, H., 2014. Behavioral Economics - Eine Einführung. Vol. 1. Springer Gabler, Pforzheim.

Berg, N., 2003. Normative Behavioral Economics. Journal of SocioEconomics 32 (4), $411-427$. 
Berg, N., Gigerenzer, G., 2010. As - if Behavioral Economics: Neoclassical Economics in Disguise. History of Economic Ideas 18 (1), 133 - 166 .

Berggren, N., 2012. Time for Behavioral Political Economy? An Analysis of Articles in Behavioral Economics. Review of Austrian Economics 25 (3), 199-221.

Bruni, L., Sugden, R., 2007. The Road Not Taken: How Psychology was Removed From Economics, And How it Might be Brought Back*. Economic Journal 117 (516), 146 - 173.

Camerer, C., 1999. Behavioral Economics: Reunifying Psychology and Economics. Proceedings of the National Academy of Sciences 96 (19), 10575 - 10577.

Camerer, C. F., Loewenstein, G., 2004. Behavioral Economics: Past, Present, Future. In: Advances in Behavioral Economics. Princeton University Press, pp. 3 - 51.

Cherrier, B., Jun. 2015. Is There a Quantitative Turn in the History of Economics (and how not to screw it up)? URL https://beatricecherrier.wordpress.com/2015/06/23/is-there-a-quantitative-turn-in-thehistory-of-economics-and-how-not-to-screw-it-up/

Cherrier, B., 2017. Classifying Economics: A History of the JEL Codes. Journal of economic literature 55 (2), $545-79$.

Claveau, F., Gingras, Y., 2016. Macrodynamics of Economics: A Bibliometric History. History of political economy $48(4), 551-592$.

Colander, D., 2000a. The Death of Neoclassical Economics. Journal of the History of Economic Thought 22 (2), $127-143$.

Colander, D., 2000b. New Millennium Economics: How Did It Get This Way, and What Way Is It? Journal of Economic Perspectives 14 (1), $121-132$.

Davis, J., 2006. The Turn in Economics: Neoclassical Dominance to Mainstream Pluralism? Journal of Institutional Economics 2 (1), 1-20.

Dow, S. C., 2014. Formalism, Rationality, and Evidence: the Case of Behavioural Economics. Erasmus Journal for Philosophy and Economics 6 (3), 26-43.

Duarte, P. G., Giraud, Y., 2016. The Place Of The History Of Economic Thought In Mainstream Economics, 1991-2011, Viewed Through A Bibliographic Survey. Journal of the History of Economic Thought 38 (4), 431462.

Earl, P. E., 2010. Economics fit for the Queen: a Pessimistic Assessment of its Prospects. Prometheus 28 (3), 209-225.

Fourcade, M., Ollion, E., Algan, Y., 2015. The Superiority of Economists. Journal of Economic Perspectives 29 (1), 89-114.

Frederick, S., Loewenstein, G., O'donoghue, T., 2002. Time Discounting and Time Preference: A Critical Review. Journal of economic literature 40 (2), 351-401.

Freeman, L. C., 1977. A Set of Measures of Centrality Based on Betweenness. Sociometry 40 (1), 35-41.

Fruchterman, T. M., Reingold, E. M., 1991. Graph Drawing by Force-Directed Placement. Software: Practice and experience 21 (11), 1129-1164.

Gingras, Y., Schinckus, C., 2012. The Institutionalization of Econophysics in the Shadow of Physics. Journal of the History of Economic Thought 34 (1), 109-130.

Glötzl, F., Aigner, E., 2015. Pluralism in the Market of Science? A Citation Network Analysis of Economic Research at Universities in Vienna. Ecological Economic Papers 5, WU Vienna University of Economics and Business, Vienna. 
Grether, D., Plott, C. R., 1979. Economic Theory of Choice and the Preference Reversal Phenomenon. American Economic Review 69 (4), $622-638$.

Grossmann, L., 2014. Das Ideal vom perfekt rationalen Verhalten - Normativität in der Verhaltensökonomik. Master's thesis, Humboldt Universität Berlin, Berlin.

Guth, W., Schmittberger, R., Schwarze, B., 1982. An Experimental Analysis of Ultimatum Bargaining. Journal of Economic Behavior \& Organization 3 (4), 367 - 388.

Hands, D. W., 2009. Economics, Psychology and the History of Consumer Choice Theory. Cambridge Journal of Economics 34 (4), 633-648.

Herfeld, C., Doehne, M., 2017. The Diffusion of Scientific Innovations: A Role Typology. Preprint. URL http://philsci-archive.pitt.edu/14229/

Heukelom, F., 2007. Who are the Behavioral Economists and what do they say? Discussion Paper 2007-020/1, Tinbergen Institute, Amsterdam.

Heukelom, F., 2014. Behavioral Economics - A History. Cambridge University Press, New York.

Kahneman, D., 2003a. Maps of Bounded Rationality: Psychology for Behavioral Economics. American Economic Review 93 (5), 1449 - 1475.

Kahneman, D., 2003b. A Psychological Perspective on Economics. American Economic Review 93 (2), 162 - 168.

Kahneman, D., Tversky, A., 1979. Prospect Theory: An Analysis of Decision under Risk. Econometrica: Journal of the Econometric Society, $263-291$.

Kapeller, J., Aistleitner, M., Steinerberger, S., 2016. The Power of Scientometrics and the Development of Economics. Working Paper 46, ICAE Working Paper Series.

Laibson, D., Zeckhauser, R., 1998. Amos Tversky and the Ascent of Behavioral Economics. Journal of Risk and Uncertainty $16(1), 7-47$.

Lee, F. S., 2012. Heterodox Economics and its Critics. Review of Political Economy 24 (2), 337-351.

Loewenstein, G., Prelec, D., 1992. Anomalies in Intertemporal Choice: Evidence and an Interpretation. Quarterly Journal of Economics 107 (2), 573 - 597.

Loomes, G., Sugden, R., 1982. Regret Theory: An Alternative Theory of Rational Choice under Uncertainty. Economic Journal 92 (368), 805-824.

Newman, M. E., 2001. Scientific Collaboration Networks. II. Shortest Paths, Weighted Networks, and Centrality. Physical review E 64 (1), 016132.

Panhans, M. T., Singleton, J. D., 2016. The Empirical Economist's Toolkit: From Models to Methods. Working Paper, Duke University, Durham.

Pesendorfer, W., 2006. Behavioral Economics Comes of Age: A Review Essay on "Advances in Behavioral Economics". Journal of Economic Literature 44 (3), 712-721.

Rabin, M., 1998. Psychology and Economics. Journal of Economic Literature 36 (1), $11-46$.

Samson, A., 2014. The Behavioral Economics Guide 2014 (with a foreword by George Loewenstein and Rory Sutherland). Vol. 1. London, UK.

SCI, 2014. SCI Journal and Country Rank.

URL http://www.scimagojr.com/journalrank.php

Sent, E.-M., 2004. Behavioral Economics: How Psychology Made Its (Limited) Way Back Into Economics. History of Political Economy 36 (4), $735-760$. 
Slovic, P., Lichtenstein, S., 1983. Preference Reversals: A Broader Perspective. American Economic Review 73 (4), $596-605$.

Thaler, R., 1980. Toward a Positive Theory of Consumer Choice. Journal of Economic Behavior \& Organization $1(1), 39-60$.

Thaler, R., 1981. Some Empirical Evidence on Dynamic Inconsistency. Economics Letters 8 (3), 201 - 207.

Thaler, R., 1985. Mental Accounting and Consumer Choice. Marketing science 4 (3), 199 - 214.

Thaler, R. H., 2016. Behavioral Economics: Past, Present, Future. American Economic Review 106 (7), 1577-1600.

Tversky, A., Kahneman, D., 1974. Judgement under Uncertainty: Heuristics and Biases. Science 185 (4157), 1124 $-1131$.

Tversky, A., Kahneman, D., 1981. The Framing of Decisions and the Psychology of Choice. Science 211 (4481), 453 $-458$.

Tversky, A., Kahneman, D., 1986. Rational Choice and the Framing of Decisions. Journal of Business 59 (4, Part 2: The Behavioral Foundations of Economic Theory), $251-278$.

Tversky, A., Kahneman, D., 1991. Loss Aversion in Riskless Choice: A Reference-Dependent Model. Quarterly Journal of Economics 106 (4), 1039-1061.

Tversky, A., Slovic, P., Kahneman, D., 1990. The Causes of Preference Reversal. American Economic Review 80 (1), 204-217.

Watts, D. J., Strogatz, S. H., 1998. Collective Dynamics of 'Small-World' Networks. Nature 393 (6684), 440. 


\section{Figures}

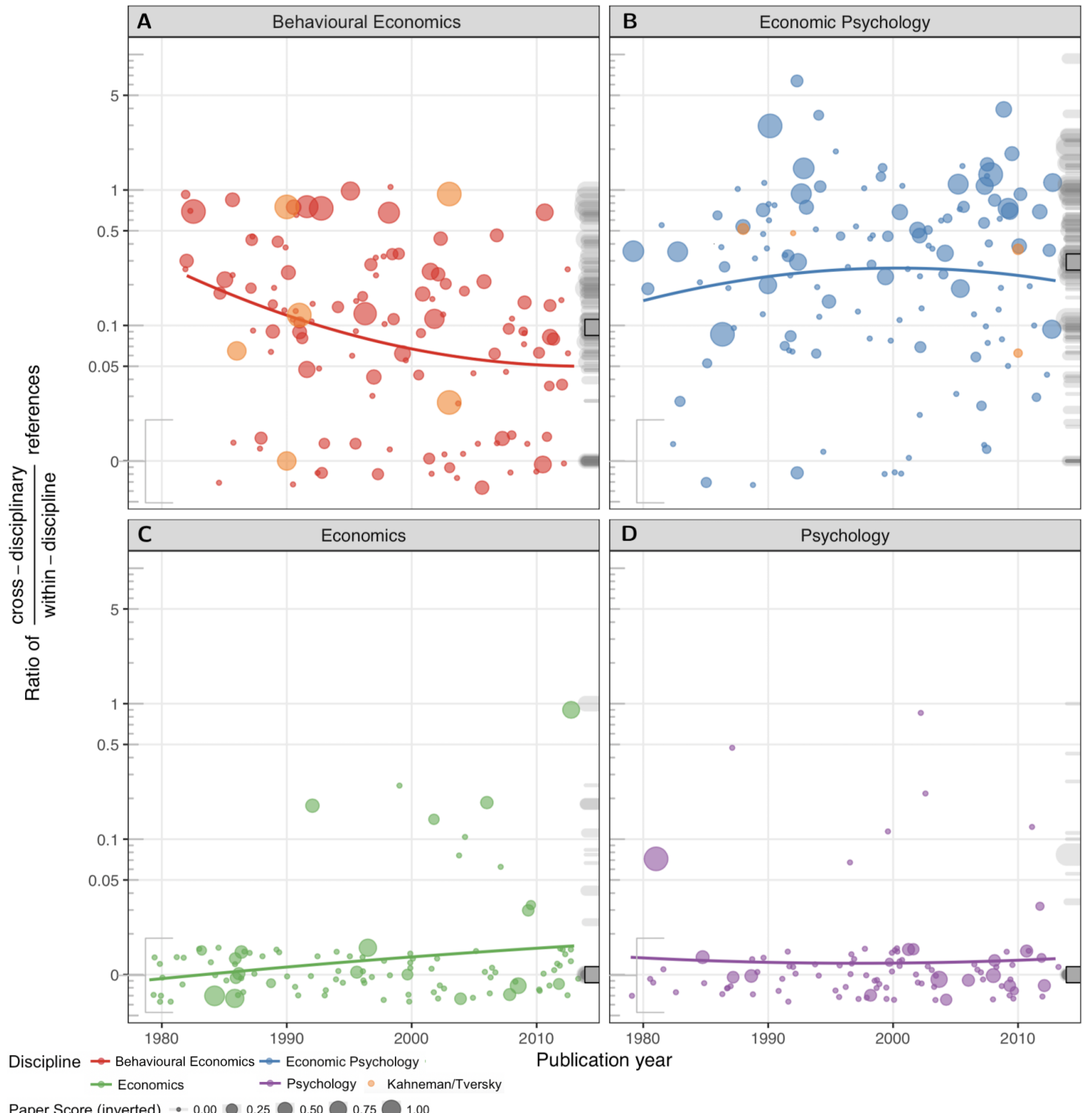

Paper Score (inverted) $\bullet 0.00 \bigcirc 0.25 \bigcirc 0.50 \bigcirc 0.75 \bigcirc 1.00$

\begin{tabular}{lccccccc} 
& \multicolumn{3}{c}{ Paper Score (inverted) } & & \multicolumn{3}{c}{ Cross-discipl. References } \\
\cline { 3 - 7 } & Mean & Median & Std.-dev. & & Mean & Median & Std.-dev. \\
Economics & 0.05 & 0.00 & 0.16 & & 0.03 & 0.01 & 0.10 \\
Behavioural Economics & 0.16 & 0.07 & 0.25 & 0.18 & 0.10 & 0.22 \\
Economic Psychology & 0.13 & 0.03 & 0.22 & 0.57 & 0.29 & 0.99 \\
Psychology & 0.04 & 0.00 & 0.15 & 0.03 & 0.01 & 0.11
\end{tabular}

Figure 1: The distribution of cross-discipline references and paper score over time 


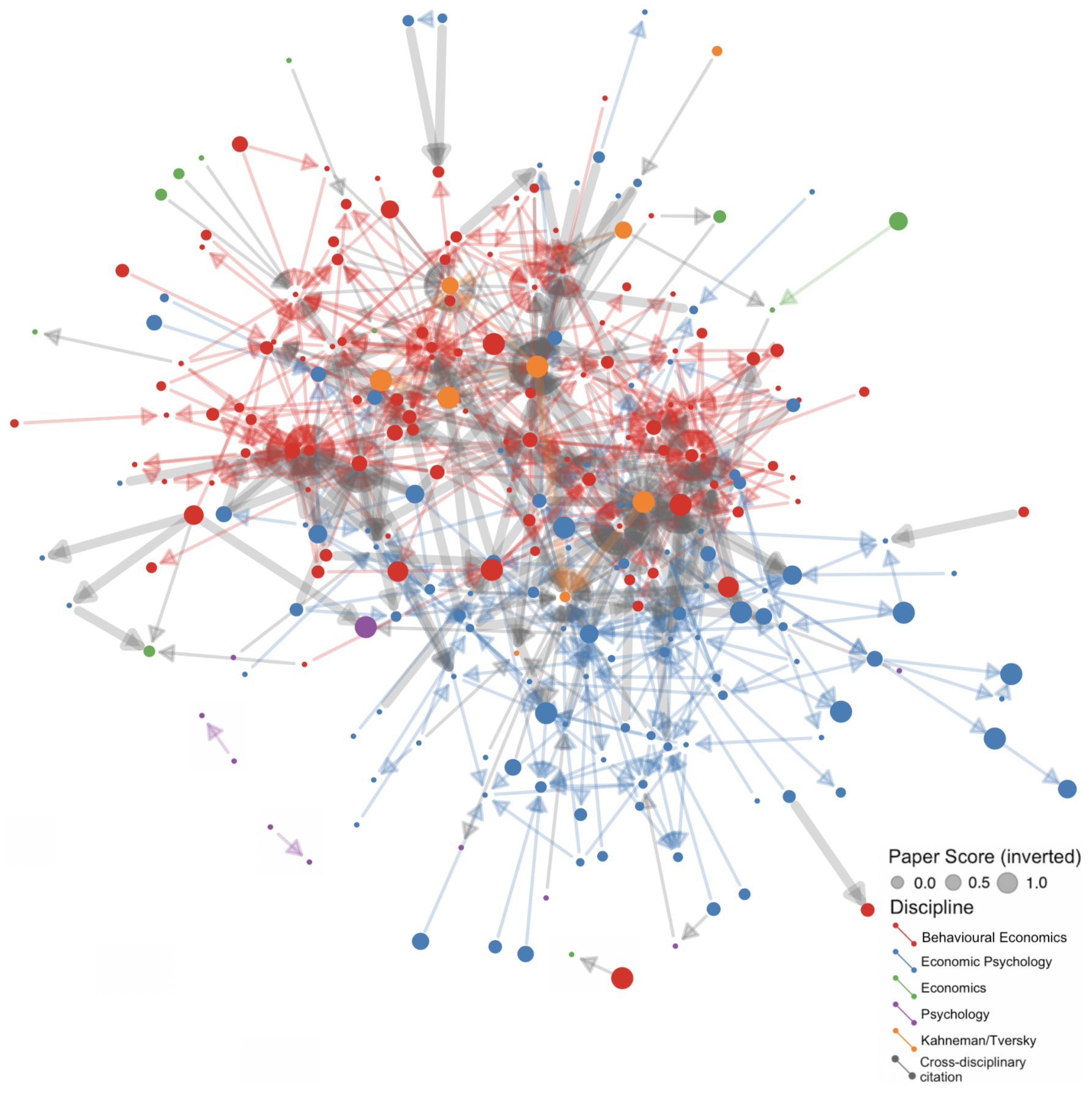

Figure 2: Cross-citation network - Each node represents an article, coloured according to the respective journal category, with at least one connection to other articles within the data set. The edges represent a citation from one article to another (directed graph). Thick grey edges represent a cross-citation link between publications in psychology journals and economics journals. 


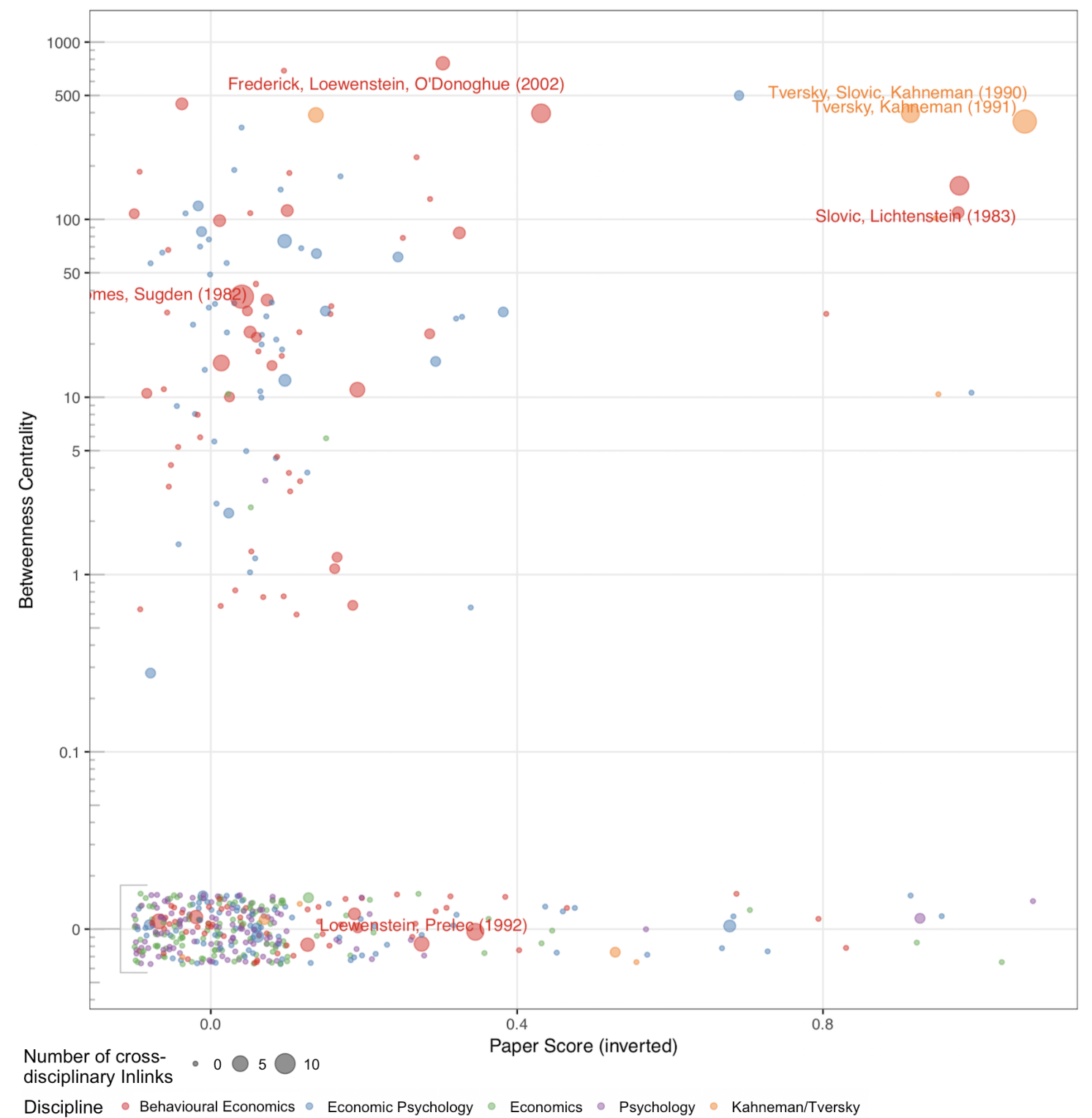

Discipline Behavioural Economics E Economic Psychology Economics • Psychology $\bullet$ Kahneman/Tversky

Tversky and Kahneman (1991)

Loomes and Sugden (1982)

Frederick et al. (2002)

Slovic and Lichtenstein (1983)

Tversky et al. (1990)

Loewenstein and Prelec (1992)

$\begin{array}{rrrr}\text { Cross-discipl. } & \begin{array}{r}\text { Betweenness } \\ \text { Centrality }\end{array} & \begin{array}{r}\text { Cross-discipl. } \\ \text { References ratio }\end{array} & \begin{array}{r}\text { Paper Score } \\ \text { (inlinks }\end{array} \\ 14 & 409 & 0.12 & 1.00 \\ 14 & 36 & 0.38 & 0.00 \\ 8 & 550 & 0.22 & 0.38 \\ 8 & 98 & 0.70 & 1.00 \\ 7 & 492 & 0.75 & 1.00 \\ 6 & 0.01 & 0.05 & 0.36\end{array}$

Figure 3: Network centrality measures

\section{Tables}


Table 1: Foundational articles of behavioural economics

\begin{tabular}{lrrlrr}
\hline Article & $\begin{array}{r}\text { Review } \\
\text { count }^{a}\end{array}$ & $\begin{array}{c}\text { Total } \\
\text { cites }^{b}\end{array}$ & Article & $\begin{array}{c}\text { Review }_{\text {count }^{a}} \\
\text { cites }^{b}\end{array}$ \\
\hline Kahneman and Tversky (1979) & 10 & 14269 & Loewenstein and Prelec (1992) & 6 & 645 \\
Tversky and Kahneman (1974) & 8 & 10005 & Guth et al. (1982) & 5 & 1493 \\
Thaler (1980) & 7 & 2866 & Tversky and Kahneman (1986) & 5 & 721 \\
Thaler (1985) & 6 & 5710 & Thaler (1981) & 4 & 671 \\
Tversky and Kahneman (1981) & 6 & 5567 & Grether and Plott (1979) & 3 & 591 \\
\hline
\end{tabular}

${ }^{a}$ Number of references to the article in all available reviews and surveys.

${ }^{b}$ Number of citations from Web of Science in August 2017. Figure for Thaler (1985) from Google Scholar.

Table 2: Top economics and psychology journals

\begin{tabular}{lc}
\hline Journal & Citations $^{a}$ \\
\hline Economics & \\
Quarterly Journal of Economics & 6.72 \\
Journal of Economic Literature & 5.83 \\
Journal of Economic Perspectives & 5.53 \\
Econometrica & 4.20 \\
European Economic Review & 3.53 \\
Review of Economic Studies & 3.45 \\
American Economic Review & 3.45 \\
Journal of Political Economy & 3.38 \\
Review of Economics and Statistics & 2.74 \\
Economic Journal & 2.46 \\
Average of top 100 economics journals & 2.89 \\
\hline Psychology & \\
Annual Review of Psychology & 22.48 \\
Trends in Cognitive Science & 14.06 \\
Psychological Bulletin & 11.63 \\
Psychological Review & 7.24 \\
Journal of Experimental Psychology: General & 5.34 \\
Psychological Science & 5.12 \\
Journal of Personality and Social Psychology & 5.08 \\
Cognitive Psychology & 4.87 \\
Journal of Applied Psychology & 4.72 \\
behavioural and Brain Sciences & 1.31 \\
Average of top 100 psychology journals & 4.52 \\
\hline${ }^{a}$ Average citations per document in a two-year period; Source: SCI (2014) & \\
&
\end{tabular}


Table 3: The use of mathematical modelling and the share of empirical articles in the different sets

(a) Mathematical modelling

\begin{tabular}{|c|c|c|c|c|c|c|c|c|c|}
\hline \multirow[b]{2}{*}{ Variable } & \multicolumn{2}{|c|}{ Economics } & \multicolumn{2}{|c|}{ Beh. Econ. } & \multirow{2}{*}{$\begin{array}{l}\text { Econ. } \\
\text { Abs. }\end{array}$} & \multirow{2}{*}{$\begin{array}{r}\text { Psych. } \\
\text { Rat. }\end{array}$} & \multicolumn{2}{|c|}{ Psychology } & \multirow[b]{2}{*}{ Sum } \\
\hline & Abs. & Rat. & Abs. & Rat. & & & Abs. & Rat. & \\
\hline Math & 81 & 24 & 76 & 18 & 51 & 08 & 11 & 01 & 219 \\
\hline No Math & 34 & 2.4 & 42 & 1.8 & 66 & 0.0 & 110 & 0.1 & 252 \\
\hline Sum & 115 & & 118 & & 117 & & 121 & & 471 \\
\hline & $\mathrm{p}=$ & $\begin{array}{l}0.708 \\
0.401\end{array}$ & & $\mathrm{p}$ & $\begin{array}{l}9.429 \\
0.002\end{array}$ & $\chi_{\mathrm{F}_{\mathrm{C}}}^{2}$ & $\mathrm{ch}=$ & $\begin{array}{l}34.981 \\
0.000\end{array}$ & \\
\hline
\end{tabular}

(b) Mathematical modelling in theoretical articles

\begin{tabular}{|c|c|c|c|c|c|c|c|c|c|}
\hline \multirow[b]{2}{*}{ Variable } & \multicolumn{2}{|c|}{ Economics } & \multirow{2}{*}{$\begin{array}{l}\text { Beh. } \\
\text { Abs. }\end{array}$} & Econ. & \multicolumn{2}{|c|}{ Econ. Psych. } & \multicolumn{2}{|c|}{ Psychology } & \multirow[b]{2}{*}{ Sum } \\
\hline & Abs. & Rat. & & Rat. & Abs. & Rat. & Abs. & Rat. & \\
\hline Math & 38 & 20 & 34 & 18 & 15 & 07 & 6 & 01 & \\
\hline No Math & 19 & 2.0 & 19 & 1.8 & 21 & 0.8 & 69 & 0.1 & 128 \\
\hline Sum & 57 & & 53 & & 36 & & 75 & & 221 \\
\hline & $\mathrm{p}$ & $\begin{array}{l}0.005 \\
0.939\end{array}$ & & $\mathrm{p}$ & $\begin{array}{l}3.518 \\
0.061\end{array}$ & $\chi_{\mathrm{Ec}}^{2}$ & $\mathrm{p}$ & $\begin{array}{l}5.845 \\
0.000\end{array}$ & \\
\hline
\end{tabular}

(c) Empirical articles

\begin{tabular}{|c|c|c|c|c|c|c|c|c|c|}
\hline \multirow[b]{2}{*}{ Variable } & \multicolumn{2}{|c|}{ Economics } & \multirow{2}{*}{$\begin{array}{l}\text { Beh. } \\
\text { Abs. }\end{array}$} & Econ. & \multirow{2}{*}{$\begin{array}{l}\text { Econ } \\
\text { Abs. }\end{array}$} & \multirow{2}{*}{$\begin{array}{c}\text { Psych. } \\
\text { Rat. }\end{array}$} & \multicolumn{2}{|c|}{ Psychology } & \multirow[b]{2}{*}{ Sum } \\
\hline & Abs. & Rat. & & Rat. & & & Abs. & Rat. & \\
\hline Data & 58 & 10 & 65 & 12 & 81 & 23 & 46 & 06 & 250 \\
\hline No Data & 57 & 1.0 & 53 & 1.2 & 36 & 2.3 & 75 & 0.0 & 221 \\
\hline Sum & 115 & & 118 & & 117 & & 121 & & 471 \\
\hline & $\mathrm{p}$ & .562 & $\chi_{\mathrm{B}}^{2}$ & $\mathrm{p}$ & $\begin{array}{l}4.413 \\
0.036\end{array}$ & & $\mathrm{p}$ & $\begin{array}{l}2.050 \\
0.000\end{array}$ & \\
\hline
\end{tabular}

